\title{
BMJ Open Readiness of health facilities and determinants to manage diabetes mellitus: evidence from the nationwide Service Provision Assessment survey of Afghanistan, Bangladesh and Nepal
}

Md Durrul Huda, ${ }^{1}$ Mosiur Rahman (10 , ${ }^{2}$ Md Mosfequr Rahman, ${ }^{2}$ Md Jahirul Islam, ${ }^{3}$ Syed Emdadul Haque, ${ }^{4}$ Md Golam Mostofa ${ }^{2}$

To cite: Huda MD, Rahman M, Rahman MM, et al. Readiness of health facilities and determinants to manage diabetes mellitus: evidence from the nationwide Service Provision Assessment survey of Afghanistan, Bangladesh and Nepal. BMJ Open 2021;11:e054031. doi:10.1136/ bmjopen-2021-054031

- Prepublication history for this paper is available online To view these files, please visit the journal online (http://dx.doi. org/10.1136/bmjopen-2021054031).

Received 02 June 2021 Accepted 09 December 2021

\section{Check for updates}

(C) Author(s) (or their employer(s)) 2021. Re-use permitted under CC BY-NC. No commercial re-use. See rights and permissions. Published by BMJ.

${ }^{1}$ Department of Diabetology, Diabetic Association Hospital, Chapai Nawabganj, Bangladesh ${ }^{2}$ Department of Population Science and Human Resource Development, University of Rajshahi, Rajshahi, Bangladesh ${ }^{3}$ Griffith Criminology Institute, Griffith University, Brisbane, Queensland, Australia

${ }^{4}$ The Public Health Sciences Department, UChicago Research Bangladesh, Dhaka, Bangladesh

Correspondence to

Dr Mosiur Rahman;

swaponru_2000@yahoo.com

\section{ABSTRACT}

Objectives Using nationally representative surveys, the study's aims were to: (1) evaluate healthcare facilities' readiness to provide diabetes mellitus (DM) services and (2) identify the factors that affect DM service readiness. Data source Data from Service Provision Assessment surveys conducted in three low-resource South Asian (SA) countries: Afghanistan, Bangladesh and Nepal, were used in this study.

Design Cross-sectional nationally representative survey Participants A total of 117, 317 and 397 public and private health facilities in Afghanistan, Bangladesh and Nepal, respectively were analysed.

Primary outcome A total of 12 items/indicators were used to measure a health facility's readiness to provide DM services across four domains.

Results For DM management, about 39.3\%, 58.4\% and $58.2 \%$ of health facilities in Afghanistan, Bangladesh and Nepal centred around 7-8, 3-6 and 4-6 items. Only $12.8 \%, 5.0 \%$ and $4.8 \%$ of healthcare facilities in Afghanistan, Bangladesh and Nepal reported having at least $\%(9 / 12)$ of the necessary items for DM management, and no one reported having all 12 important items for DM management. According to the negative binomial regression models, the factors associated with higher readiness scores vary among the three countries analysed. Regression models also showed that increases in the number of DM care providers and facility types are similar factors linked to increased readiness scores in all three countries.

Conclusions In order to increase a health facility's readiness to offer DM care, country-specific factors must be addressed in addition to common factors found in all three countries. Further research is required to determine the cause of country-level differences in tracer item availability in order to develop targeted and effective country-specific strategies to improve care quality in the SA region.

\section{INTRODUCTION}

Diabetes mellitus (DM), a chronic metabolic disease, is a major public health problem around the world. DM has reached epidemic

\section{Strengths and limitations of this study}

- This is the first multicounty study to assess the state of diabetes service readiness in three low-resource South Asian countries: Afghanistan, Bangladesh and Nepal, as well as the factors that influence diabetes service readiness in those countries.

- The data were analysed using the most recent nationally representative sample of public and private health facilities, including a large number of health facilities.

- The outcome variables were developed using measures from the WHO-Service Availability and Readiness Assessment manual that reflected the clinical reality of the research.

- The cross-sectional nature of the study limits the potential to show a causal relationship between the suggested determinants and the readiness scores.

proportions in South Asia (SA) as a result of epidemiological transformation brought on by urbanisation and shifts in demographics, lifestyle and population structure. ${ }^{1}$ By 2045 , it is projected that 152.8 million adults aged 20-79 years in SA will have DM, almost double the amount reported in $2019 .{ }^{2} \mathrm{DM}$ has been steadily increasing in Afghanistan, Bangladesh and Nepal within the SA region. In 2019, the prevalence of DM was $9.2 \%$ in Afghanistan, $7.2 \%$ in Nepal and 9.2\% in Bangladesh. ${ }^{2}$ DM-related deaths among people under 60 years old in Afghanistan, Bangladesh and Nepal were $83.4 \%, 63.1 \%$ and $49.2 \%$, respectively, in the same year. ${ }^{2}$

To combat the immense burden of DM-related mortality and morbidity, increased DM diagnosis and treatment is crucial. ${ }^{3}$ However, in the countries surveyed, a significant number of people have undiagnosed DM. In Afghanistan, Bangladesh and 
Nepal, for example, $73.4 \%, 56 \%$ and $69.5 \%$ had undiagnosed DM, respectively. ${ }^{2}$ A lack of healthcare accessibility, availability and utilisation could explain the higher prevalence of undiagnosed DM in such countries. ${ }^{2}$ Furthermore, only a small percentage of the diagnosed patients were receiving care in the countries under investigation. ${ }^{2}$ Improving the readiness of the health facilities to provide DM services is one factor that can help with DM diagnosis and treatment. ${ }^{4}$

Health facilities in the SA countries are thought to be inadequately prepared to deal with the burden of DM because of weak health systems. ${ }^{5}$ In high-burden, systemconstrained countries like Afghanistan, Bangladesh and Nepal, evaluating the health facilities readiness to provide DM services is critical for identifying gaps and the potential for further development in DM care. Such information is needed to notify policymakers about how to improve health services and reduce the increased burden of DM-related mortality and morbidity.

To date, a number of studies have been conducted in order to generate detailed subnational and national assessments of health facility general service readiness, ${ }^{67}$ as well as readiness for disease-specific studies on maternal and child health, ${ }^{89}$ family planning, ${ }^{10}{ }^{11}$ sexually transmitted infections and HIV testing and counselling, ${ }^{12}$ and tuberculosis. ${ }^{13}$ Studies have also been performed to assess the readiness of healthcare facilities to deal with major non-communicable diseases (NCDs) including cardiovascular disease,${ }^{14-17}$ hypertension ${ }^{17-20}$ and chronic respiratory disease. ${ }^{151621}$ While the readiness of health facilities on some major NCDS has been assessed, there has yet to be an empirically validated generalisable analysis of DM readiness in low-resource setting in the literature.

Low readiness to provide DM services was identified in a few studies conducted in Bangladesh, ${ }^{14} 1622{ }^{23} \mathrm{Nepal}^{15}$ Ethiopia, ${ }^{24} 25$ Tanzania, ${ }^{18} 192627$ Uganda $^{20}$ and Zambia. ${ }^{17}$ The majority of previous research on DM care readiness in low-resource settings, however, relied on proxy indicators consisting of general inputs such as numbers of health workers and hospital beds ${ }^{28}$ or was limited to local or regional samples. ${ }^{16} 181922-24$ Since most previous research in this field used small sample sizes or unrepresentative samples or did not use a standard measuring instrument to determine readiness, the findings may be biased. Furthermore, previous studies in this field that were focused on national surveys were mostly conducted in one country. However, multicounty studies are needed in order to present a comparative presentation of facility ability to provide DM services for countries with similar sociocultural features.

Furthermore, the majority of previous smallscale $^{17-1922-24}$ or single-country studies ${ }^{142025}$ in lowresource settings have failed to identify potential readiness factors. According to Tanzanian research, ${ }^{26}{ }^{27}$ facilities in urban settings, higher level (health centres and hospitals) and publicly run facilities, facilities where regular management meetings were held, having a source of funding other than the government, and the presence of medical doctors were all associated with a higher service readiness index for providing outpatient management of DM. Place and provincial differences in DM service readiness scores were discovered in Nepalese study. ${ }^{15}$ Lack of training, unavailability of medicine and insufficient supervision were found to be relevant to achieving DM service readiness in the Bangladeshi study. ${ }^{16}$

While certain aspects of a health system's readiness to provide DM services have been reported, further research is needed into other factors such as client usage costs, external supervision, the number of trained DM care providers, the presence of trained doctors 24 hours a day and the health facility's diagnostic and treatment ability. The objectives of this study were to: (1) evaluate the state of DM service readiness in three low-resource SA countries namely Afghanistan, Bangladesh and Nepal and (2) determine the factors associated with DM service readiness in the countries under investigation.

\section{METHODS}

\section{Data sources}

The sample of the study consisted of health facilities from three countries in the SA region that had participated in Demographic and Health Surveys (DHSs) to assess service provision, namely the 2018-2019 Afghanistan Service Provision Assessment survey (AfSPA 2018-2019), ${ }^{29}$ the 2014 Bangladesh Health Facility Survey (BHFS 2014), ${ }^{30}$ the 2015 Nepal Health Facility Survey (NHFS 2015). ${ }^{31}$ We obtained data from Monitoring and Evaluation to Assess and Use Results Demographic and Health Surveys (MEASURE DHS) Archive (https://dhsprogram. com/data/dataset/Afghanistan_SPA_2018.cfm?flag=1; https://dhsprogram.com/data/dataset/Bangladesh_ SPA_2017.cfm?flag=1; https://dhsprogram.com/data/ dataset/Nepal_SPA_2015.cfm?flag=1). A detailed description for obtaining the access and permission to analyse the DHS data is available (https://dhsprogramcom/data/ Using-DataSets-for-Analysiscfm). The AfSPA, NHFS and BFHS are national-representative surveys of both public and private hospitals and clinics performed by ICF Macro (Rockville, Maryland, USA) as part of the MEASURE DHS project, which was sponsored by the United States Agency for International Development (USAID). Four main questionnaires are included in the Service Provision Assessment (SPA) surveys: (1) facility inventory questionnaire. (2) healthcare provider interview questionnaire; (3) observation protocols and (4) questionnaire on exit interviews. Only the data from the facility inventory questionnaire was used in this analysis.

The AfSPA, NHFS and BFHS were created to collect data on health facility availability and readiness in the areas of maternal and child health, family planning, selected NCDs and tuberculosis. ${ }^{29-31}$ In accordance with standard health facility protocol, the survey also assesses the availability of human resources, basic facilities and logistics, such as supplies, vital medications, laboratory services and infection prevention measures. The AfSPA, 


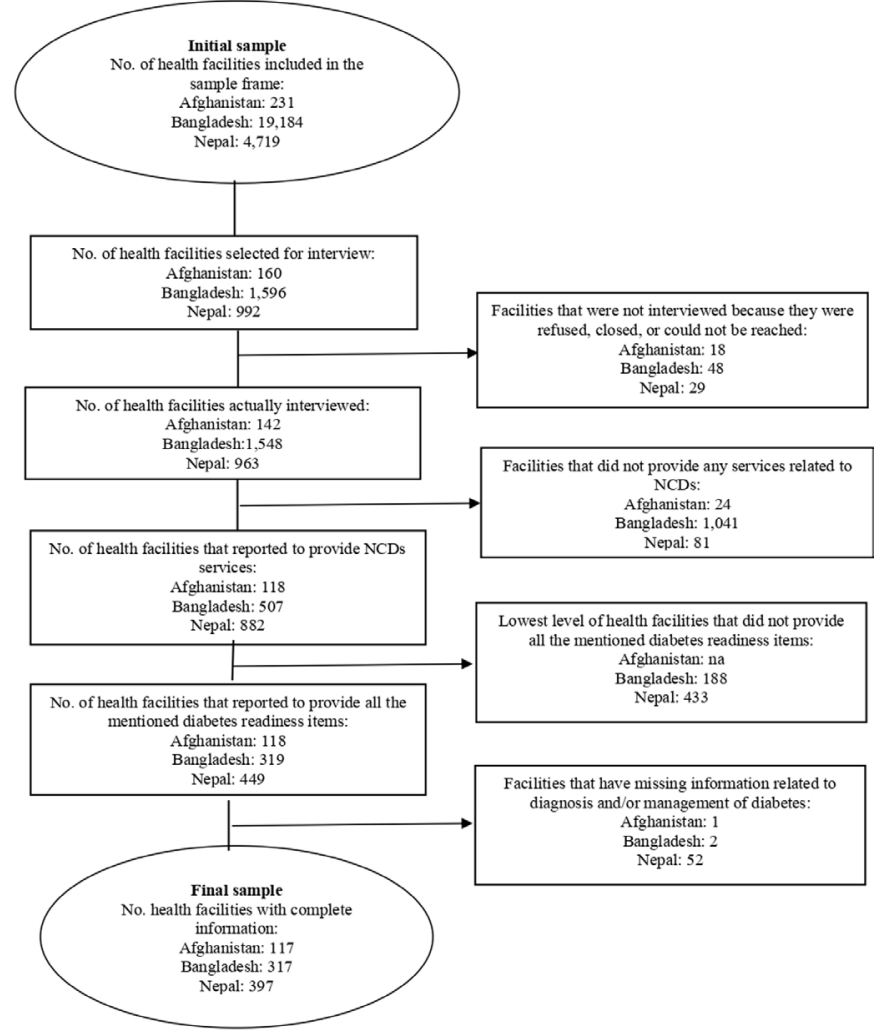

Figure 1 Selection of the sample: Afghanistan, Bangladesh and Nepal Service Provision Assessment survey.

NHFS and BFHS questionnaires were written in English and then translated into the national language of each country. The DHS Programme's core SPA questionnaires were fitted and tailored to the country's situation and needs. The WHO-SARA (Service Availability and Readiness Assessment for Hospitals ${ }^{4}$ methods were also updated and adapted.

Kabul, Nangarhar, Paktya, Kunduz, Balkh, Kandahar and Herat were among the seven major provinces where the AfSPA 2018-2019 was conducted concurrently. ${ }^{29}$ Except in Kabul, all public and private hospitals and private clinics were included in six provinces, while in Kabul, all private and private hospitals were included, but 13 of 84 private clinics were chosen at random. The survey included 160 facilities (public hospitals, private hospitals and private clinics) from all seven provinces. After excluding those with missing values, our study included 117 healthcare facilities (figure 1).

The BHFS 2014 sample included 19184 registered facilities from seven administrative divisions across the country (Barisal, Chittagong, Dhaka, Khulna, Rajshahi, Rangpur and Sylhet) ${ }^{30}$ District hospitals (DHs), maternal and child welfare centres, Upazila health complexes (UHCs), upgraded Union health and family welfare centres, Union health and family welfare centres, Union subcenters/rural dispensaries and community clinics were all included, as were private hospitals with at least 20 beds and non-governmental organisation (NGO) static clinics/hospitals. A total of 1596 health facilities in the formal sector were chosen for the survey using a stratified random sampling method from a total of 19184 (stratified according to administrative unit and type of facilities). It should be noted that health facilities up to the subdistrict level (UHCs) in Bangladesh provide services for NCDs. As a result, facilities below the subdistrict level and those with missing values were removed from our study. In the end, 317 healthcare facilities were considered (figure 1)

NHFS 2015 contained a total of 963 health facilities. ${ }^{31}$ All government and private hospitals, primary healthcare centres (PHCCs), health posts (HPs), stand-alone HIV testing and counselling (HTC) centres, and urban health centres (UHCs) were included in the study sample. The NHFS 2015 study was a stratified random sample of health facilities chosen with equal probability systematic sampling and sample allocation. Within each domain, stratification was accomplished by separating the health facilities by facility type/management authority. We chose PHCCs and government and private hospitals for the current analyses because most of the WHO-SARA general service readiness measures are supposed to be available in higher-level facilities, such as PHCCs and above, while HP, UHCs and standalone HTCs are not required to include all of the listed readiness items of service readiness. The survey comprised 397 facilities after excluding HPs, UHCs and stand-alone HTCs, as well as missing data (figure 1).

Each of the countries being investigated, the details about the health facility's service availability and readiness were given by the manager, the facility's person-in-charge, or the most senior health worker responsible for client services present at the facility. The interviewers checked for the existence of any identified equipment or supplies that were valid or functional.

\section{MEASURES}

\section{Outcome}

Readiness of health facility to manage DM was the outcome variable in this analysis. This was a composite measure that was generated as a counting score based on the number of vital indicators required for DM services within the facility. The WHO-SARA ${ }^{4}$ four reference manual suggested four domains for evaluating service provision readiness, and a total of 12 items/indicators were identified from those four domains: (1) staff and guideline components; (2) equipment and supplies components; (3) components related to diagnostic tools and (4) components related to medicine and comorbidities.

Two indicators were used to evaluate the domain of staff and guidelines: (1) availability of DM diagnosis and treatment guidelines and (2) at least one staff member delivering the service trained in DM diagnosis and treatment in the 24 months prior to the survey. The second domain, components of the equipment and supplies for DM services was evaluated by means of three indicators: existence of (1) digital blood pressure (BP) machine 
or manual sphygmomanometer with a stethoscope; (2) adult weighing scale and (3) stadiometer.

The third domain is 'diagnostic', which has three indicators: (1) the presence of a functional glucometer with test strips; (2) the presence of a urine dipstick for protein and (3) the presence of a urine dipstick for ketones. Medicines and comorbidities, the fourth and final domain, was evaluated based on the availability of four forms of medicine: (1) metformin; (2) glibenclamide; (3) injectable insulin and (4) injectable glucose solution. To determine the availability of each of the 12 indicators, binary variables was established, either as presence or absence. The readiness score was then totaled by adding each indicator's presence (observed and seen by the interviewers). Each indicator's contribution to the overall score was given equal weight. The obtained readiness score was used as the outcome variable, which was calculated as a counting score based on the availability of 12 WHO-SARA indicators. Scores range from 0 to 12.

\section{Explanatory variables}

The explanatory variables were chosen based on two criteria: (1) they were available in the SPA survey ${ }^{29-31}$ and (2) previous research had established them as important determinants of readiness of health facilities to provide DM services. ${ }^{14-27}$ The following variables were considered: facility location, managing authority, facility type, external sources of revenue, quality assurance activities, routine management meetings, external supervision, user fees, presence of trained health provider at facility 24 hours with duty schedule or present on-call, feedback on clients' opinions, health facility's' ability to perform diagnosis and/or treatment, and number of trained DM care providers.

The facility's location was classified as either rural or urban. To assess managing authority, a dichotomous variable was generated (public: facilities owned by the government, or private: facilities not owned by the government). External revenue sources were classified according to whether the facilities obtained additional (extra) financial assistance from the government, NGOs or none at all. A dichotomous variable was developed to measure quality assurance activities (yes: facility that reported to routinely carry out quality assurance activities, eg, review of mortality, or audit of registers within the past 12 months or no: facilities that did not report to routinely carry out quality assurance activities).

External supervision was categorised as 'yes' for the facility that received supportive supervision from a higher authority such as district or region health management team in the past 12 months, otherwise, the facility was coded as 'no'. Routine management meetings were measured using a dichotomous variable (performed: whether the facility reported having regular management meetings at least once every 2-3 months or not performed). A categorical variable was also created to describe user fees as either none, a separate charge for each service provided to patients, or a fixed fee for all services. The presence of trained health provider at facility 24 hours with duty schedule or present on-call was categorised as yes versus no.

We divided the facility's diagnosis and/or treatment capacity into three categories: having both diagnosis and treatment capacity, having only diagnosis capacity and having only treatment capacity. The system for collecting client opinion was divided into two categories: reviewed and unreviewed. Since the variable facility type was measured by country, it was classified as national/provincial hospital, special hospital, or private hospital/clinic in Afghanistan, NGO clinic/hospital, private clinic/hospital, UHC or DH in Bangladesh, and government hospitals, private hospitals or PHCCs in Nepal. The number of DM providers is treated as a discrete quantitative variable.

\section{Statistical analyses}

First, descriptive analyses were performed to provide general information on the sample's characteristics. Continuous variables were summarised in the descriptive analysis using either mean (SD) for normally distributed variables or median (IQR) for non-normally distributed variables. The proportions were used to summarise all categorical variables, which were then described in tables and graphs. Chi-square tests were used to compare the availability of 12 essential items for health facility readiness to provide DM services between the countries.

Since our outcome variable was a count variable and the variable had overdispersion, negative binomial regression model was used to estimate the impact of each selected explanatory variable on the facility's readiness to manage DM. In a negative binomial regression model, we calculated incidence rate ratios (IRRs). All explanatory variables were entered into the multiple regression models at the same time. $\mathrm{P}$ value $<0.05 \%$ and $95 \%$ CI for IRRs were used to confirm the significance of the association. All estimates were weighted to correct for non-response and disproportionate sampling. We did not combine the data sets in our research; rather, we studied each data set separately, therefore we did not denormalize the weights of the pooled data. Data were analysed using Stata V.16 (StataCorp).

\section{Patient and public involvement}

The study participants were not involved in the design of this study.

\section{RESULTS}

\section{Characteristics of surveyed facilities}

Table 1 displays the distribution of surveyed facilities in Afghanistan, Bangladesh and Nepal based on their background characteristics. In the three countries surveyed, the majority of the facilities were privately owned, and the majority of the facilities provided DM diagnosis and treatment. In Bangladesh, approximately $44 \%$ of facilities reported receiving funds from sources other than the government, such as user fees, faith-based organisations, 
Table 1 Percentage distribution of surveyed facilities according to background characteristics: Afghanistan, Bangladesh and Nepal Service Provision Assessment survey

\begin{tabular}{|c|c|c|c|c|c|c|}
\hline \multirow[b]{2}{*}{ Variables } & \multicolumn{2}{|c|}{ Afghanistan $(n=117)$} & \multicolumn{2}{|c|}{ Bangladesh $(n=317)$} & \multicolumn{2}{|c|}{ Nepal $(n=397)$} \\
\hline & $\mathbf{n}$ & $\%(95 \% \mathrm{Cl})$ & $\mathbf{n}$ & $\%(95 \% \mathrm{Cl})$ & $\mathbf{n}$ & $\%(95 \% \mathrm{Cl})$ \\
\hline \multicolumn{7}{|l|}{ Facility location } \\
\hline Rural & na & na & 72 & 22.7 (17.2 to 29.2$)$ & na & na \\
\hline Urban & & & 245 & 77.4 (71.0 to 82.8 ) & & \\
\hline \multicolumn{7}{|l|}{ Managing authority } \\
\hline Private & 97 & 89.0 (82.4 to 93.2) & 127 & 60.6 (54.0 to 66.8 ) & 141 & 55.5 (49.3 to 61.5$)$ \\
\hline Public & 20 & $11.0(6.8$ to 17.6$)$ & 190 & 39.4 (33.2 to 46.0$)$ & 256 & 44.5 (38.5 to 50.7 ) \\
\hline \multicolumn{7}{|l|}{ Facility type* } \\
\hline NGO clinic/hospital & na & na & 68 & 35.9 (28.9 to 43.5$)$ & na & na \\
\hline Private clinic/hospital & & & 71 & 29.8 (23.7 to 36.7 ) & & \\
\hline $\mathrm{UHC}$ & & & 119 & 29.2 (23.9 to 35.2$)$ & & \\
\hline District hospital & & & 59 & 5.1 (3.8 to 6.7$)$ & & \\
\hline \multicolumn{7}{|l|}{ Facility type $†$} \\
\hline Government hospitals & na & na & na & na & 100 & 17.6 (14.2 to 21.6$)$ \\
\hline Private hospitals & & & & & 141 & 55.5 (49.3 to 61.5$)$ \\
\hline PHCCs & & & & & 156 & $26.9(22.6$ to 31.7$)$ \\
\hline \multicolumn{7}{|l|}{ Facility typeł } \\
\hline National/provincial & 8 & 4.4 (2.1 to 9.0$)$ & na & na & na & na \\
\hline \multicolumn{7}{|l|}{ Hospital } \\
\hline Special hospital & 14 & 7.7 (4.4 to 13.4 ) & & & & \\
\hline Private hospital/clinic & 95 & 87.8 (81.1 to 92.4$)$ & & & & \\
\hline \multicolumn{7}{|l|}{ External sources of revenue } \\
\hline None & 32 & $28.2(17.7$ to 41.8$)$ & 30 & 16.5 (11.7 to 22.9$)$ & 36 & 9.7 (6.4 to 14.5$)$ \\
\hline Other than government & 25 & 17.7 (10.0 to 29.3$)$ & 96 & 43.7 (36.7 to 51.0$)$ & 233 & $43.0(38.0$ to 49.3$)$ \\
\hline Government & 60 & 54.1 (40.5 to 67.1$)$ & 191 & 39.8 (33.5 to 46.5$)$ & 128 & 47.2 (40.6 to 54.0$)$ \\
\hline \multicolumn{7}{|l|}{$\begin{array}{l}\text { Routine quality assurance } \\
\text { activities }\end{array}$} \\
\hline No & 79 & $73.6(61.7$ to 82.8$)$ & 192 & 66.9 (60.1 to 73.0$)$ & 305 & 79.9 (74.7 to 84.3$)$ \\
\hline Yes & 38 & 26.4 (17.2 to 38.3$)$ & 125 & 33.1 (27.0 to 40.0$)$ & 92 & 20.1 (15.7 to 25.3$)$ \\
\hline \multicolumn{7}{|c|}{ Routine management meetings } \\
\hline Not performed & 19 & 15.5 (8.2 to 27.4$)$ & na & na & 52 & $11.9(8.4$ to 16.6$)$ \\
\hline Performed & 98 & 84.5 (72.6 to 91.8$)$ & & & 345 & 88.1 (83.4 to 91.6$)$ \\
\hline \multicolumn{7}{|l|}{ External supervision } \\
\hline No & 8 & $12.3(4.6$ to 29.0$)$ & 35 & 13.9 (9.6 to 19.6$)$ & 27 & 8.3 (5.2 to 13.2$)$ \\
\hline Yes & 109 & 87.7 (71.1 to 95.4$)$ & 282 & 86.1 (80.4 to 90.4$)$ & 370 & 91.7 (86.8 to 94.9$)$ \\
\hline \multicolumn{7}{|l|}{ User fees } \\
\hline None & 15 & $8.3(4.8$ to 14.1$)$ & 78 & 20.7 (16.0 to 26.5$)$ & 31 & 5.3 (3.7 to 7.6$)$ \\
\hline Separate fees & 8 & $12.4(4.7$ to 29.0$)$ & 38 & $10.5(6.9$ to 15.9$)$ & 22 & $4.8(2.9$ to 8.0$)$ \\
\hline Fixed for all services & 94 & $79.3(65.3$ to 88.7$)$ & 201 & 68.7 (62.1 to 74.7$)$ & 344 & 89.8 (86.2 to 92.5$)$ \\
\hline \multicolumn{7}{|c|}{ Presence of health provider, 24 hours } \\
\hline No & 33 & 30.8 (19.3 to 45.3$)$ & 69 & 34.1 (27.4 to 41.5$)$ & 142 & $35.3(29.3$ to 41.9$)$ \\
\hline Yes & 84 & 69.2 (54.7 to 80.7$)$ & 248 & 65.9 (58.5 to 72.6$)$ & 255 & $64.7(58.1$ to 70.7$)$ \\
\hline \multicolumn{7}{|l|}{ Clients' opinions } \\
\hline Not reviewed & 88 & 60.1 (44.8 to 73.6$)$ & 223 & 69.5 (62.8 to 75.6$)$ & 273 & 73.6 (67.9 to 78.6$)$ \\
\hline
\end{tabular}


Table 1 Continued

\begin{tabular}{|c|c|c|c|c|c|c|}
\hline \multirow[b]{2}{*}{ Variables } & \multicolumn{2}{|c|}{ Afghanistan $(n=117)$} & \multicolumn{2}{|c|}{ Bangladesh $(n=317)$} & \multicolumn{2}{|c|}{ Nepal $(n=397)$} \\
\hline & $\mathbf{n}$ & $\%(95 \% \mathrm{Cl})$ & $\mathbf{n}$ & $\%(95 \% \mathrm{Cl})$ & $\mathbf{n}$ & $\%(95 \% \mathrm{Cl})$ \\
\hline Reviewed & 29 & 39.9 (26.4 to 55.2) & 94 & 30.5 (24.5 to 37.2$)$ & 124 & 26.4 (21.4 to 32.1$)$ \\
\hline \multicolumn{7}{|l|}{ Ability to perform } \\
\hline Diagnosis and treat & 98 & 80.9 (66.5 to 90.0$)$ & 197 & 59.0 (51.8 to 65.8 ) & 315 & 83.0 (78.3 to 86.9$)$ \\
\hline Only diagnosis & 15 & 12.8 (6.1 to 25.0 ) & 101 & 35.3 (28.8 to 42.4$)$ & 72 & 14.2 (10.8 to 18.5$)$ \\
\hline Only treat & 4 & 6.3 (1.6 to 22.3$)$ & 19 & $5.7(3.1$ to 10,4$)$ & 10 & 2.7 (1.3 to 5.9$)$ \\
\hline
\end{tabular}

No. of diabetes care providers

Median (IQR)

$$
3(1,4) \quad \text { na } 2(1,3) \text { na } 2(1,3) \text { na }
$$

${ }^{\star}$ Facility type was measured for Bangladesh.

†Facility type was measured for Nepal.

łFacility type was measured for Afghanistan.

na, data are not available; NGO, non-governmental organisation; PHCC, primary healthcare centre; UHC, urban health complex.

donor agencies and so on, while the majority of facilities in Afghanistan (54.1\%) and Nepal (47.2\%) reported receiving funds from the government.

Routine quality assurance procedures were not performed, client opinions were not reviewed and patient fees were set for all services in the majority of health facilities in the countries surveyed. Afghanistan had a higher median (IQR) number of diabetes providers 3 (1-4) than Bangladesh 2 (1-3) and Nepal 2 (1-3).

\section{Availability of diabetes services}

Table 2 shows the distribution of guidelines, equipment, diagnostic instruments and medicines among surveyed facilities by country. Significantly, Bangladesh had the highest percentage of DM guidelines available $(33.1 \%)$ in the health facilities evaluated, while Nepal had the lowest $(3.4 \%)$ and Afghanistan had a higher proportion of at least one member of staff trained in DM. Blood

Table 2 Percentage distribution of surveyed facilities according to availability of guidelines, equipment, diagnostic tools and drugs: Service Provision Assessment survey, Afghanistan Bangladesh and Nepal

\begin{tabular}{|c|c|c|c|c|}
\hline & $\begin{array}{l}\text { Afghanistan } \\
(\mathrm{n}=117)\end{array}$ & $\begin{array}{l}\text { Bangladesh } \\
(\mathrm{n}=317)\end{array}$ & $\begin{array}{l}\begin{array}{l}\text { Nepal } \\
(n=397)\end{array} \\
\end{array}$ & \\
\hline Variables & $\%(95 \% \mathrm{Cl})$ & $\%(95 \% \mathrm{Cl})$ & $\%(95 \% \mathrm{Cl})$ & P value* \\
\hline \multicolumn{5}{|l|}{ Staff and guideline } \\
\hline Presence of guidelines & 18.5 (12.2 to 27.2 ) & 33.1 (27.1 to 39.8$)$ & 3.4 (2.2 to 5.4$)$ & $<0.001$ \\
\hline Availability of trained staff & $18.0(9.1$ to 32.5$)$ & $12.8(9.0$ to 18.0$)$ & 2.1 (1.2 to 3.7$)$ & $<0.001$ \\
\hline \multicolumn{5}{|l|}{ Equipment and supplies } \\
\hline BP apparatus & 93.4 (78.0 to 98.3$)$ & 97.5 (94.3 to 98.9$)$ & 96.3 (92.4 to 98.2) & 0.378 \\
\hline Weight scale & 70.5 (58.4 to 80.2$)$ & 77.1 (70.6 to 82.6$)$ & 91.4 (87.3 to 94.2$)$ & $<0.001$ \\
\hline Height scale & 43.1 (29.8 to 57.4$)$ & 52.4 (45.4 to 59.4$)$ & 35.6 (29.6 to 42.2 ) & 0.082 \\
\hline \multicolumn{5}{|l|}{ Diagnostic tools } \\
\hline Glucometer with test strips & 36.8 (24.7 to 50.8$)$ & 44.7 (37.8 to 51.7$)$ & 18.5 (13.8 to 24.4$)$ & $<0.001$ \\
\hline Urine protein test & 86.7 (74.6 to 93.6 ) & 57.1 (50.1 to 63.9) & 79.9 (74.0 to 84.7$)$ & $<0.001$ \\
\hline Urine glucose test & 87.9 (75.6 to 94.5$)$ & 54.1 (47.1 to 61.0$)$ & 81.4 (75.9 to 85.9$)$ & $<0.001$ \\
\hline \multicolumn{5}{|l|}{ Medicines and commodities } \\
\hline Metformin & $82.8(71.2$ to 90.4$)$ & $28.0(22.2$ to 34.6$)$ & 54.3 (47.9 to 60.6$)$ & $<0.001$ \\
\hline Glibenclamide & 46.1 (32.9 to 59.8) & 18.9 (14.1 to 24.8$)$ & 21.4 (16.2 to 27.8$)$ & $<0.001$ \\
\hline Injectable insulin & 44.7 (32.3 to 57.8$)$ & 19.7 (14.6 to 25.9 ) & 31.3 (24.9 to 38.6$)$ & 0.001 \\
\hline Injectable glucose solution & 84.0 (69.0 to 92.5$)$ & 22.3 (17.2 to 28.5 ) & 70.4 (64.1 to 75.9$)$ & $<0.001$ \\
\hline
\end{tabular}

${ }^{*} \chi^{2}$ test was performed.

$\mathrm{BP}$, blood pressure. 

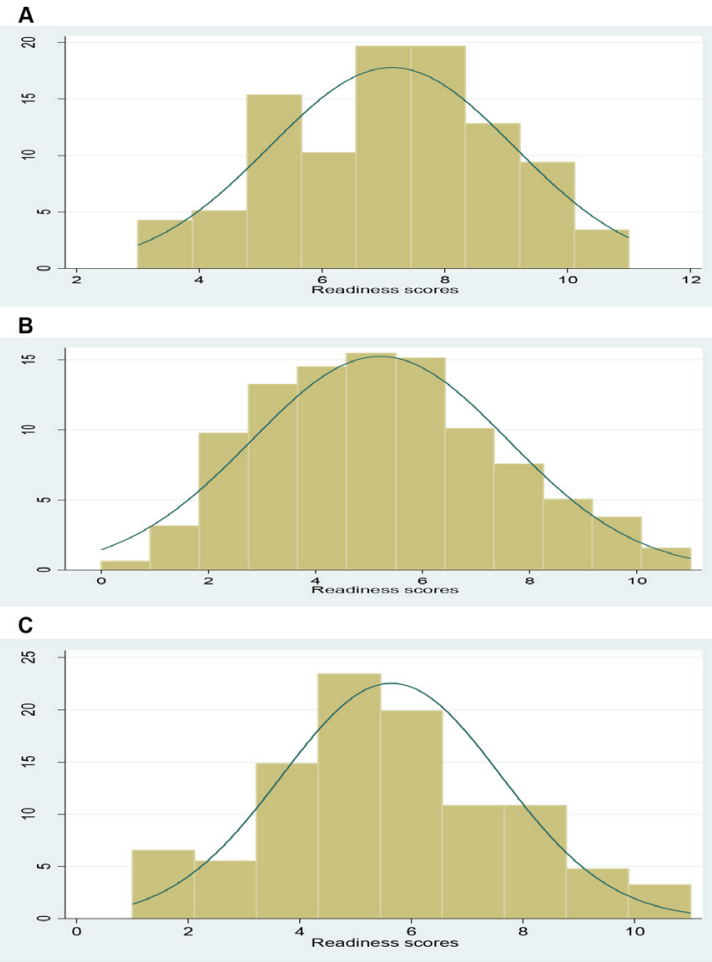

Figure 2 Percentage distribution of surveyed facilities according to readiness score: Service Provision Assessment survey of (A) Afghanistan, (B) Bangladesh and (C) Nepal.

pressure monitors were readily available in all three countries' healthcare facilities. When it came to adult weighing scale availability, significantly Nepal had the highest percentage when compared with Bangladesh and Afghanistan, and when it came to height scale availability, Bangladesh had the highest percentage when compared with counterparts.

In comparison to Bangladesh, significantly, Afghanistan and Nepal had a higher percentage of urine protein and urine glucose tests available. However, when it came to glucometers with test strips, significantly, Bangladesh had the highest percentage compared with Nepal and Afghanistan. Bangladesh had the lowest percentage healthcare facilities that offered DM medication. Metformin was provided at higher rates in all of the health facilities studied in the country.

\section{Survey facilities' readiness score}

Figure 2 presents the histogram of readiness score based on the 12 important items for providing management of DM in Afghanistan, Bangladesh and Nepal. The majority of the facilities in Afghanistan were clustered around 7-8 scores $(39.3 \%)$, while the majority of the facilities in Bangladesh were clustered around 3-6 scores (58.4\%) and the majority of the facilities in Nepal were clustered around 4-6 scores $(58.2 \%)$. The histogram also indicates that in all of the health facilities examined in the three countries, no one reported having all 12 important items for DM management.

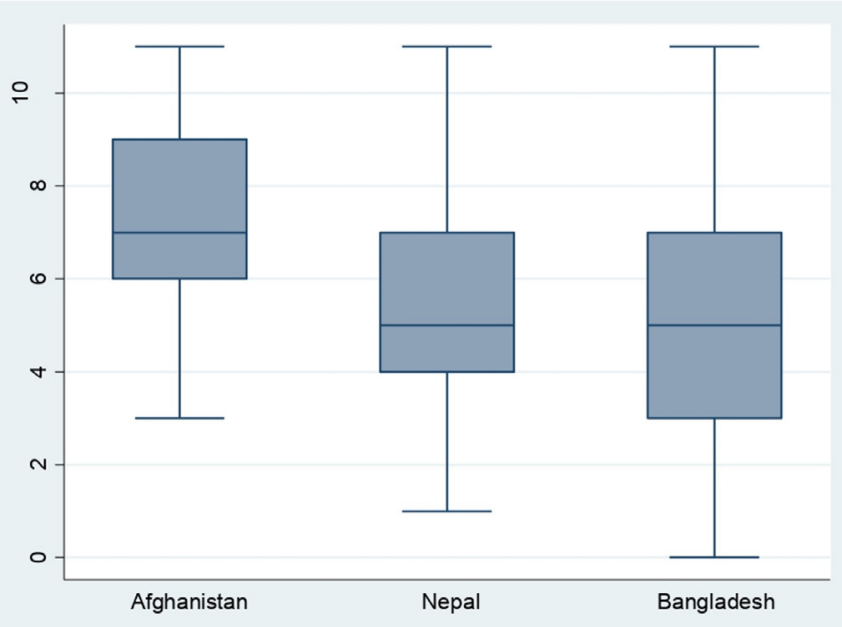

Figure 3 Overall distribution of readiness score to manage diabetes mellitus according to country. Box shows the limits of $25 \%$ and $75 \%$ percentile. The horizontal line inside the box shows the median value. The bar shows the low and upper limits of $95 \% \mathrm{Cl}$.

The boxplot presented in figure 3 showed that Afghanistan, Bangladesh and Nepal had median readiness scores (IQR) of 7 (6-9), 5 (3-7) and 5 (4-7), respectively. For Afghanistan, Bangladesh and Nepal only 15 (12.8\%), 16 $(5.0 \%), 19(4.8 \%)$, of all facilities reported having at least $75 \%(9 / 12)$ of the important items.

\section{Factors associated with readiness to manage diabetes}

The results of the negative binomial regression model analysis for variables related to health facility readiness to manage DM in the countries under study are shown in table 3 .

Provided that the other variables in the model remain unchanged, the readiness score for Afghanistan is expected to fall by $50 \%$ (IRR $0.50 ; 95 \%$ CI 0.37 to 0.66 ) for public managing authority versus private, $25 \%$ (IRR 0.75 ; $95 \%$ CI 0.57 to 0.99 ) and $53 \%$ (IRR $0.47 ; 95 \%$ CI 0.33 to 0.69 ) lower for special hospital and private hospital/clinic versus national/provincial hospital, and 23\% (IRR 0.77; $95 \%$ CI 0.62 to 0.95$)$ lower when the external sources of revenue were other than the government compared with none. When the health facility could only perform treatment rather than diagnosis and treatment, the readiness score was $16 \%$ lower (IRR $0.84 ; 95 \%$ CI 0.77 to 0.92 ). When compared with their counterparts, the presence of trained healthcare provider, 24 hours, external supervision and when the external source of revenue is government were associated with $24 \%, 34 \%$ and $11 \%$ increase in readiness score in Afghanistan, respectively.

In Bangladesh, the readiness score is expected to rise by $30 \%$ (IRR 1.30; 95\% CI 1.08 to 1.57 ) for private clinics/ hospitals versus NGO clinics/hospitals, 23\% (IRR 1.23; $95 \%$ CI 1.03 to 1.48 ) for d fixed user fees versus none and $20 \%$ (IRR 1.20; 95\% CI 1.03 to 1.39) for the presence of trained healthcare providers versus none. On the other 
Table 3 Models of negative binomial regression for variables associated with health facility readiness to manage diabetes mellitus: Afghanistan, Bangladesh and Nepal Service Provision Assessment survey

\begin{tabular}{|c|c|c|c|}
\hline \multirow[b]{3}{*}{ Variables } & Afghanistan & Bangladesh & Nepal \\
\hline & $(n=117)$ & $(n=317)$ & $(n=397)$ \\
\hline & \multicolumn{3}{|l|}{ IRR (95\% Cl) } \\
\hline \multicolumn{4}{|l|}{ Facility location } \\
\hline Rural & na & 1 & na \\
\hline Urban & & 0.93 (0.79 to 1.09$)$ & \\
\hline \multicolumn{4}{|l|}{ Managing authority } \\
\hline Private & 1 & 1 & 1 \\
\hline Public & $0.50(0.37 \text { to } 0.66)^{\star}$ & 1.06 (0.82 to 1.36$)$ & 0.95 (0.86 to 1.04$)$ \\
\hline \multicolumn{4}{|l|}{ Facility type $†$} \\
\hline NGO clinic/hospital & na & 1 & na \\
\hline Private clinic/hospital & & $1.30(1.08 \text { to } 1.57)^{\star *}$ & \\
\hline $\mathrm{UHC}$ & & $0.63(0.47 \text { to } 0.86)^{\star \star}$ & \\
\hline District hospital & & 0.77 (0.57 to 1.03$)$ & \\
\hline \multicolumn{4}{|l|}{ Facility typeł } \\
\hline Government hospitals & na & na & 1 \\
\hline Private hospitals & & & - \\
\hline PHCCs & & & $0.75(0.69 \text { to } 0.83)^{\star}$ \\
\hline \multicolumn{4}{|l|}{ Facility type§ } \\
\hline National/provincial hospital & 1 & na & na \\
\hline Special hospital & $0.75(0.57 \text { to } 0.99)^{\star \star \star}$ & & \\
\hline Private hospital/clinic & $0.47(0.33 \text { to } 0.69)^{*}$ & & \\
\hline \multicolumn{4}{|l|}{ External sources of revenue } \\
\hline None & 1 & 1 & 1 \\
\hline Other than government & $0.77(0.62 \text { to } 0.95)^{\star \star \star}$ & 1.06 (0.87 to 1.30$)$ & 1.05 (0.92 to 1.21$)$ \\
\hline Government & $1.11(1.01 \text { to } 1.21)^{\star \star \star}$ & 1.19 (0.90 to 1.56$)$ & 1.03 (0.89 to 1.20$)$ \\
\hline \multicolumn{4}{|c|}{ Routine quality assurance activities } \\
\hline No & 1 & 1 & 1 \\
\hline Yes & 0.99 (0.91 to 1.08$)$ & 1.07 (0.96 to 1.20$)$ & 0.93 (0.82 to 1.06$)$ \\
\hline \multicolumn{4}{|l|}{ Routine management meetings } \\
\hline Not performed & 1 & - & 1 \\
\hline Performed & 1.08 (0.96 to 1.21$)$ & & 0.95 (0.86 to 1.06$)$ \\
\hline \multicolumn{4}{|l|}{ External supervision } \\
\hline No & 1 & 1 & 1 \\
\hline Yes & $1.34(1.11 \text { to } 1.61)^{\star \star}$ & 1.05 (0.87 to 1.29$)$ & 1.09 (0.94 to 1.25$)$ \\
\hline \multicolumn{4}{|l|}{ User fees } \\
\hline None & 1 & 1 & 1 \\
\hline Separate fees & $1.10(0.81$ to 1.50$)$ & 1.11 (0.86 to 1.44$)$ & 0.85 (0.63 to 1.13$)$ \\
\hline Fixed for all services & 0.88 (0.64 to 1.20$)$ & $1.23(1.03 \text { to } 1.48)^{\star \star \star}$ & 1.07 (0.92 to 1.24$)$ \\
\hline \multicolumn{4}{|c|}{ Presence of health provider, 24 hours } \\
\hline No & 1 & 1 & 1 \\
\hline Yes & $1.24(1.12 \text { to } 1.37)^{\star}$ & $1.20(1.03 \text { to } 1.39)^{\star \star}$ & 0.99 (0.91 to 1.07$)$ \\
\hline \multicolumn{4}{|l|}{ Clients' opinions } \\
\hline Not reviewed & 1 & 1 & 1 \\
\hline Reviewed & 0.98 (0.90 to 1.07$)$ & 1.01 (0.89 to 1.15$)$ & 0.95 (0.88 to 1.02$)$ \\
\hline
\end{tabular}




\begin{tabular}{|c|c|c|c|}
\hline \multirow[b]{3}{*}{ Variables } & Afghanistan & Bangladesh & Nepal \\
\hline & $(n=117)$ & $(n=317)$ & $(n=397)$ \\
\hline & \multicolumn{3}{|l|}{ IRR (95\% CI) } \\
\hline Diagnosis and treat & 1 & 1 & 1 \\
\hline Only diagnosis & 1.00 (0.89 to 1.13$)$ & $1.03(0.91$ to 1.17$)$ & 0.98 (0.85 to 1.13$)$ \\
\hline No. of diabetes care providers & $1.02(1.01 \text { to } 1.04)^{\star * *}$ & $1.06(1.02 \text { to } 1.10)^{\star \star}$ & $1.03(1.00 \text { to } 1.06)^{\star \star \star}$ \\
\hline
\end{tabular}

${ }^{*} \mathrm{P}<0.001,{ }^{* *}<0.01,{ }^{* * *}<0.05$.

†Facility type was measured for Bangladesh.

¥Facility type was measured for Nepal.

§Facility type was measured for Afghanistan.

IRR, incidence risk ratio; na, data were not available; NGO, non-governmental organisation.

hand, the readiness score is expected to decrease by $37 \%$ for UHCs versus NGO clinics/hospitals in Bangladesh.

In Nepal, the readiness score for PHCCs versus government hospitals is predicted to drop by $25 \%$ (IRR 0.75 ; $95 \% \mathrm{CI} 0.69$ to 0.83 ). If the number of DM care providers rises by one unit (per provider), the readiness score will grow by $0.0002,0.0006$ and 0.0003 in Afghanistan, Bangladesh and Nepal, respectively.

\section{DISCUSSION}

This is the first multicounty study to assess the state of DM service readiness in three low-resource SA countries: Afghanistan, Bangladesh and Nepal, as well as the factors that influence DM service readiness in those countries. There are three major findings: (1) in all three countries surveyed, just $12.8 \%, 5.0 \%$ and $4.8 \%$ healthcare facilities in Afghanistan, Bangladesh and Nepal reported having at least $75 \%$ (9/12) of the important items for DM management, and no one reported having all 12 important items for DM management; (2) with the exception of the BP apparatus and the height scale, the countries varied significantly in their availability of all tracer objects and (3) although the factors linked to increased readiness scores differed by countries, facility types and increases in the number of DM care providers are similar factors linked to increased readiness scores in all three countries.

The observed low readiness of health facilities to provide DM care in the three countries under investigation suggests that health systems in those low-resource settings face major challenges in delivering DM prevention and treatment services. In some previous small-scale studies in Bangladesh ${ }^{162223}$ and Nepal, ${ }^{32}$ inadequate readiness of health facilities to provide DM services was also stated. Similar challenges have been discovered in other low-income and middle-income countries. ${ }^{17-20} 24-27$ To combat the growing DM epidemic, these results therefore indicate that health facilities' readiness to provide DM services in these low-resource countries should be strengthened.
The findings also revealed that there were differences in the availability of tracer items between countries. In Nepal, for example, compared with Afghanistan and Bangladesh, the percentage of facilities with DM guidelines and at least one staff member trained in DM was extremely low. Furthermore, DM guidelines were more likely to appear in health facilities in each country than DM-trained workers. This is concerning because even though protocols are available in a facility, they might not be followed if employees are not trained to do so.

According to the WHO proposed ${ }^{33}$ an $80 \%$ availability goal for key DM medicines to control DM, only metformin and injectable glucose solution are available in more than $80 \%$ of health facilities in Afghanistan; however, the current study found significant low availability of essential antidiabetic drugs in health facilities throughout the country, with the situation in Bangladesh deteriorating. As a result, this reflects the sluggish speed at which these countries are dealing with the increasing burden of DM. Inadequacy of essential anti-diabetic medication in health facilities has also been documented in other low-resource settings. ${ }^{17-20} 24-27$

The availability of basic diagnostic equipment has been shown to affect early DM diagnosis and clinical management. ${ }^{34}$ The availability of glucometers and testing strips is lower in all countries, according to this study, despite the fact that a higher percentage of urine protein and urine glucose diagnostic instruments are available (in Nepal and Afghanistan, this proportion ranges from $80 \%$ and above). It is possible that the higher percentage of urine test strips available than glucose test strips is due to the lower cost of urine test strips compared with a blood glucose monitor and test strips. ${ }^{35}$ However, since blood tests are more precise and can determine the exact amount of glucose in the blood ${ }^{36}$ these findings allow responsible authorities and various health stakeholders to consider the increased availability of glucometers with test strips in the countries under investigation. 
Specialist hospitals and private hospitals/clinics in Afghanistan are less likely to be ready to provide DM services than national/provincial hospitals. This is plausible because the government predominantly funds national/provincial hospitals in Afghanistan, and DM care is primarily given in those hospitals. ${ }^{37}$ The readiness scores for providing DM services in UHCs and PHCCs in Bangladesh and Nepal were rather low. UHCs and PHCCs act as a hub for primary healthcare facilities that primarily serve the rural population seeking treatment for NCDs. As a result, the findings suggest that Bangladesh's and Nepal's primary healthcare systems are still lacking in their ability to combat DM and other NCDs. This is in direct opposition to WHO efforts to prioritise the introduction of Package for Essential NCDs strategies in primary healthcare facilities in low-resource settings for the management of NCDs. ${ }^{38}$

Maintaining a sufficient number of health professionals is critical to achieving a balance between human and physical resources and ensuring the system's effectiveness. ${ }^{39}$ In all three countries examined, the connection between an increase in the number of DM care providers and an increase in the readiness of health facilities to provide DM services is plausible, because when healthcare consumables like drugs, supplies and diagnostic instruments are readily available, it has the potential to impact the ability of healthcare systems to recruit and retain specialists in their fields in order to keep the system working.

The readiness scores of privately managed facilities in Afghanistan were higher than those of publicly managed facilities, according to the current study. These findings are in line with those of previous studies conducted in low-resource settings. ${ }^{2640}$ The possible explanation is that, since privately owned facilities are managed for profit, their management authorities are more accountable and devoted to patients, and therefore tend to provide more quality services in order to gain more clients and profit.

In comparison to facilities in Afghanistan that did not have external supervision, this study found that having external supervision was associated with a higher readiness score. This result is in line with a recent smallscale study conducted in Bangladesh, ${ }^{16}$ which found that external supervision of health facilities is linked to DM readiness. Another randomised controlled trial in Zimbabwe ${ }^{41}$ found that health facilities with supervision had substantially improved stock management metrics than those without supervision.

According to the results, higher readiness scores in Afghanistan were also related to external sources of revenue from the government. This finding is consistent with the findings of a multicounty study ${ }^{7}$ that found that receiving fund from external agencies was related to the health facilities' overall general service readiness. The availability of trained health providers 24 hours a day in health facilities in Afghanistan and Bangladesh, as well as the facility's ability to perform both diagnosis and treatment, were found to be more likely to be associated with increased readiness scores in this study. These findings are probable because these two indicators are the drivers of certain health facilities' increased capacity to provide essential DM management items.

Although there is still conflicting evidence ${ }^{42} 43$ about the impact of user fees on people's attendance at health facilities, our research found that user fee (fixed for all services) was associated with a higher readiness to provide DM services in Bangladesh. Owing to a lack of government investment, health facilities in Bangladesh are often short on recurrent inputs such as medicines and other medical supplies. ${ }^{44}$ As a result, increased cost-recovery revenues from consumer fees may be used to enhance healthcare quality, effectiveness and coverage.

The current research has a number of strengths. To begin, the data were analysed using the most recent nationally representative sample of public and private health facilities from three countries in the SA region, including a large number of health facilities (Afghanistan: $\mathrm{n}=117$; Bangladesh: $\mathrm{n}=317$ and Nepal: $\mathrm{n}=397$ ). Second, to ensure standardisation and comparability across different sites and periods, the SPA employs comprehensive interviewer preparation, standardised measuring tools and techniques, and the same core questionnaire, as well as pretesting tools. ${ }^{29-31}$ Third, the outcome variables were developed using measures from the WHO-SARA manual ${ }^{4}$ that reflected the clinical reality of the research. Finally, the existence or absence of protocols, equipment, diagnostic instruments and medications in the health facility was recorded based on the observations of trained survey enumerators.

The findings discussed here are subject to a number of limitations. First, since the study was conducted using a cross-sectional sample, causality conclusions could not be inferred. As a result, the current results should be viewed with caution. Second, the availability of SPA surveys limited our country selection, as we only examined SPA data from three SA countries, which cannot be applied to other countries in the region. Third, although this research used data from SPA surveys to look at the availability of drugs, equipment's diagnostics and guidelines, many other tools and resources for DM management, such as electrocardiograms and other technologies, were not considered.

Fourth, the BHFS 2014 only collected data from public primary and secondary care facilities, as well as private/ NGO facilities in the countries surveyed that only offered DM services; no data were collected from higher-level facilities, such as tertiary-level health facilities. This is something that should be considered in future research, so that policymakers can make informed decisions. Fifth, we were unable to collect data from patients, which would have given further insight from the perspective of service users but was beyond the reach of this study. Sixth, since no literature exists on the relative weight of each DM tracer item on the WHO-SARA instrument, we used equivalent weights for all items in the DM-specific readiness scores. This may have underestimated or exaggerated the extent of DM service readiness. In order to improve the validity 
of a DM readiness metric, future studies can consult DM healthcare experts (ie, using Delphi methods).

Finally, although the WHO-SARA tracer items used to build the DM readiness scores allow for a broad assessment of DM service capacity, items related to microvascular complications screening, such as retinopathy and neuropathy, were left out. Since early detection of these complications is critical for optimal DM care, including questions about them in future health facility surveys may allow for the development of more comprehensive DM management tools.

\section{CONCLUSIONS}

We found that health facility capacity to provide DM services is lacking in three countries with high diabetes prevalence. In these countries, only a small percentage of health facilities have at least $75 \%(9 / 12)$ of the required DM management items, and no one has all 12 tracer items. With the exception of the BP apparatus and the height scale, the countries differed greatly in their availability of all tracer objects. Although the factors associated with higher readiness scores vary between the three nations, the number of DM care providers and facility types are all related to higher readiness scores. In order to increase a health facility's readiness to offer DM care, country-specific factors must be addressed in addition to common factors found in all three countries. Further research is required to determine the cause of countrylevel differences in tracer item availability in order to develop targeted and effective country-specific strategies to improve care quality in the SA region.

Acknowledgements The authors express their gratitude to the MEASURE DHS for providing the dataset. The authors also acknowledge all individuals and institutions involved in carrying out the SPA survey in Afghanistan, Bangladesh and Nepal.

Contributors MR acts as guarantor. MDH and MR were the ones who came up with the idea for the study, performed the key statistical analyses and wrote the first draft of the manuscript. MMR, MJI, SEH and MGM provided feedback on the statistical analyses as well as the draft manuscript. MGM supervises the study while MR cosupervises it. The final study was read and approved by all contributors.

Funding The authors have not declared a specific grant for this research from any funding agency in the public, commercial or not-for-profit sectors.

Competing interests None declared.

Patient and public involvement Patients and/or the public were not involved in the design, or conduct, or reporting, or dissemination plans of this research.

Patient consent for publication Consent obtained directly from patient(s).

Ethics approval This study involves human participants and the current findings were based on an overview of existing databases for the public domain survey, which are freely accessible online with disconnected information for all identifiers. The SPA survey has been approved by the ethical review boards of each country's Ministry of Health and ICF International's institutional review board in the USA. However, the DHS survey report does not provide the ID or reference number for ethical approval to public access. All the study procedures were conducted in accordance with the principles of the Declaration of Helsinki as revised in 2013 specimen collection. Participants gave informed consent to participate in the study before taking part.

Provenance and peer review Not commissioned; externally peer reviewed.

Data availability statement Data are available in a public, open access repository. Data are available in a public, open access repository. Data are available on the website (https://dhsprogram.com/data/Access-Instructions.cfm).
Open access This is an open access article distributed in accordance with the Creative Commons Attribution Non Commercial (CC BY-NC 4.0) license, which permits others to distribute, remix, adapt, build upon this work non-commercially, and license their derivative works on different terms, provided the original work is properly cited, appropriate credit is given, any changes made indicated, and the use is non-commercial. See: http://creativecommons.org/licenses/by-nc/4.0/.

ORCID iD

Mosiur Rahman http://orcid.org/0000-0002-0612-8369

\section{REFERENCES}

1 Jayawardena R, Ranasinghe P, Byrne NM, et al. Prevalence and trends of the diabetes epidemic in South Asia: a systematic review and meta-analysis. BMC Public Health 2012;12:380.

2 International Diabetes Federation. IDF diabetes atlas. Eighth ed, 2017. www.diabetesatlas.org

3 Rahman M, Nakamura K, Kizuki M. Socioeconomic differences in the prevalence, awareness, and control of diabetes in Bangladesh. $J$ Diabetes Complications 2015;29:788-93.

4 WHO service availability and readiness assessment (SARA). Available: http://www.who.int/healthinfo/systems/sara_indicators_ questionnaire/en/ [Accessed 30 Aug 2013].

5 Maher D, Harries AD, Zachariah R, et al. A global framework for action to improve the primary care response to chronic noncommunicable diseases: a solution to a neglected problem. BMC Public Health 2009:9:355.

6 Ministry of Health. Uganda services availability and readiness assessment 2013. summary report: key findings in figures. Kampala, Uganda: Ministry of Health, 2013.

7 Leslie HH, Spiegelman D, Zhou X, et al. Service readiness of health facilities in Bangladesh, Haiti, Kenya, Malawi, Namibia, Nepal, Rwanda, Senegal, Uganda and the United Republic of Tanzania. Bull World Health Organ 2017;95:738-48.

8 Wang W, Mallick L, Allen C, et al. Effective coverage of facility delivery in Bangladesh, Haiti, Malawi, Nepal, Senegal, and Tanzania. PLoS One 2019;14:e0217853.

9 Winter R, Yourkavitch J, Wang W, et al. Assessment of health facility capacity to provide newborn care in Bangladesh, Haiti, Malawi, Senegal, and Tanzania. J Glob Health 2017;7:020509.

10 Ali M, Farron M, Ramachandran Dilip T, et al. Assessment of family planning service availability and readiness in 10 African countries. Glob Health Sci Pract 2018:6:473-83.

11 Mpunga D, Lumbayi JP, Dikamba N, et al. Availability and quality of family planning services in the Democratic Republic of the Congo: high potential for improvement. Glob Health Sci Pract 2017;5:274-85.

12 Acharya K, Thapa R, Bhattarai N, et al. Availability and readiness to provide sexually transmitted infections and HIV testing and counselling services in Nepal: evidence from comprehensive health facility survey. BMJ Open 2020;10:e040918.

13 Oluwasanu MM, Hassan A, Adebayo AM, et al. General and tuberculosis-specific service readiness in two states in Nigeria. BMC Health Serv Res 2020;20:792.

14 Biswas T, Haider MM, Das Gupta R, et al. Assessing the readiness of health facilities for diabetes and cardiovascular services in Bangladesh: a cross-sectional survey. BMJ Open 2018;8:e022817.

15 Ghimire U, Shrestha N, Adhikari B, et al. Health system's readiness to provide cardiovascular, diabetes and chronic respiratory disease related services in Nepal: analysis using 2015 health facility survey. BMC Public Health 2020;20:1163.

16 Alam W, Nujhat S, Parajuli A, et al. Readiness of primary healthcare facilities for the management of non-communicable diseases in rural Bangladesh: a mixed methods study. Lancet Glob Health 2020;8:S17.

17 Mutale W, Bosomprah S, Shankalala P, et al. Assessing capacity and readiness to manage NCDS in primary care setting: gaps and opportunities based on adapted WHO Pen tool in Zambia. PLoS One 2018;13:e0200994.

18 Adinan J, Manongi R, Temu GA, et al. Preparedness of health facilities in managing hypertension \& diabetes mellitus in Kilimanjaro, Tanzania: a cross sectional study. BMC Health Serv Res 2019;19:537.

19 Peck R, Mghamba J, Vanobberghen F, et al. Preparedness of Tanzanian health facilities for outpatient primary care of hypertension and diabetes: a cross-sectional survey. Lancet Glob Health 2014;2:e285-92.

20 Isadru VR, Nanyonga RC, Alege JB. Health facilities' readiness to manage hypertension and diabetes cases at primary health facilities 
in Bidibidi refugee settlement, Yumbe district, Uganda. $J$ Trop Med 2021;2021:1415794.

21 Paromita P, Chowdhury HA, Mayaboti CA, et al. Assessing service availability and readiness to manage chronic respiratory diseases (CRDs) in Bangladesh. PLoS One 2021;16:e0247700.

22 Islam MR, Laskar SP, Macer D. A study on service availability and readiness assessment of non-communicable diseases using the WHO tool for Gazipur district in Bangladesh. BJBio 2016;7:1-13.

23 Rawal LB, Kanda K, Biswas T, et al. Non-communicable disease (NCD) corners in public sector health facilities in Bangladesh: a qualitative study assessing challenges and opportunities for improving NCD services at the primary healthcare level. BMJ Open 2019;9:e029562.

24 Tafese F, Teferi E, Wondafirash B. Readiness of primary health care facilities in Jimma zone to provide diabetic services for diabetic clients, Jimma zone, South West Ethiopia, March, 2013. J Metab Syndr 2016;5:214

25 Abebe B, Theodros G, Kassahun A. Service availability and readiness for diabetes care at health facilities in Ethiopia. Ethiop $J$ Health Dev 2017:31:110-8.

26 Bintabara D, Shayo FK. Disparities in availability of services and prediction of the readiness of primary healthcare to manage diabetes in Tanzania. Prim Care Diabetes 2021:15:365-71.

27 Bintabara D, Ngajilo D. Readiness of health facilities for the outpatient management of non-communicable diseases in a lowresource setting: an example from a facility-based cross-sectional survey in Tanzania. BMJ Open 2020;10:e040908.

28 Bollyky TJ, Templin T, Cohen M, et al. Lower-income countries that face the most rapid shift in noncommunicable disease burden are also the least prepared. Health Aff 2017;36:1866-75

29 Ministry of Public Health, Afghanistan, and ICF. Afghanistan service provision assessment 2018-19. Kabul, Afghanistan: Ministry of Public Health, Afghanistan, and ICF, 2019.

30 National Institute of Population Research and Training (NIPORT), Associates for Community and Population Research (ACPR), and ICF International. Bangladesh health facility survey 2014. Dhaka, Bangladesh: NIPORT, ACPR, and ICF International, 2016.
31 Ministry of Health, Nepal; New ERA, Nepal; Nepal Health Sector Support Program (NHSSP) and ICF 2017. Nepal health facility survey. Kathmandu, Nepal: Ministry of Health, Nepal, 2015.

32 Aryal BK, Daud M, Thapa A, et al. Assesssment of health facilities for implementation of non-communicable disease package. J Nepal Health Res Counc 2018;16:149-55.

33 European diabetes leadership forum. The diabetes epidemic and its impact on Europe. Copenhagen, 2012.

34 WHO. Implementation tools: package of essential noncommunicable (PEN) disease interventions for primary health care in low-resource settings. Geneva: World Health Organization, 2013.

35 Rahman M, Nakamura K, Hasan SMM, et al. Mediators of the association between low socioeconomic status and poor glycemic control among type 2 diabetics in Bangladesh. Sci Rep 2020;10:6690.

36 Storey HL, van Pelt MH, Bun S, et al. Diagnostic accuracy of selfadministered urine glucose test strips as a diabetes screening tool in a low-resource setting in Cambodia. BMJ Open 2018;8:e019924.

37 Ministry of Public Health. National strategy for prevention and control of noncommunicable disease (NCDS) 2015-2020. General Directorate of Preventive Medicine, Noncommunicable disease control directorate, Afghanistan.

38 World Health Organization. Package of essential noncommunicable disease interventions for primary health care in low-resource settings. Geneva: World Healh Organization, 2010.

39 Kabene SM, Orchard C, Howard JM, et al. The importance of human resources management in health care: a global context. Hum Resour Health 2006;4:20.

40 Basu S, Andrews J, Kishore S, et al. Comparative performance of private and public healthcare systems in low- and middle-income countries: a systematic review. PLoS Med 2012;9:e1001244.

41 Trap B, Todd $\mathrm{CH}$, Moore $\mathrm{H}$, et al. The impact of supervision on stock management and adherence to treatment guidelines: a randomized controlled trial. Health Policy Plan 2001;16:273-80.

42 Creese AL. User charges for health care: a review of recent experience. Health Policy Plan 1991;6:309-19.

43 Gilson L. The lessons of user fee experience in Africa. Health Policy Plan 1997:12:273-85.

44 Islam A, Biswas T. Health system in Bangladesh: challenges and opportunities. AJHR 2014;2:366-74. 